\title{
Role of Education of People in Charge of Facilities Producing Pastry in Avoiding the Use of Food Colors
}

\author{
Fereshteh Farzianpour1, a*, Shayan Hosseini2,b,Shadi Hosseini3,c and
}

Seyed Shahab Hosseini4, d

1Department of Health Management and Economics, School of public health

Tehran University ofMedical sciences. Tehran, Iran

2Amir Kabir University, Tehran, Iran

3,4,5Department of Management, Tehran University, Tehran, Iran

afarzianp@sina.tums.ac.ir, briercom@yahoo.com,2

cShadi197927@yahoo.com, dshahabhosseini@aol.com

*Corresponding author

\begin{abstract}
Training of foodstuff producers as a group effective on the quality of food materials is an important factor in achievement of food safety. This was an analytical interventional study, which was performed in a cross-sectional manner in 10 months. The target population consisted of 180 individuals in charge of facilities producing pastry in Iran. The participants were categorized into three groups;faceto-face training, distance training, and control groups. The data was collected using a questionnaire, which evaluated the knowledge, attitude, practice, and good manufacturing practices. The data were analyzed by (X2) and Ttest.According to the results of T-test, the mean knowledge scores before and after the intervention were significantly different in the face-to-face and distance training groups $(\mathrm{p}<0.05)$.
\end{abstract}

Keywords: Education, Producing Pastry, Food Colors.

\section{Introduction}

Human health, as the crucial element of sustainable development, is a major concern of politicians and authorities of different countries [1, 2]. Food-borne diseases annually cause millions of cases of morbidity and mortality around the world [2]. According to the reports of the center for disease control (CDC), each year 76 millions of individuals are affected by the disease in the USA, due to which 325,000 cases of hospitalization and 5200 deaths occur. Food materials are one of the main sources of microbial and chemical contamination. In this respect, it is estimated that $70 \%$ of the infectious diseases are transmitted to human via contaminated food, and more than 450 types of viral, parasitic, fungal, and microbial diseases are transmitted to human through foods of animal origin [3],bringing the annual medical cost of 6.5-34.9 billion dollars $[4,5]$. However, the World Health Organization (WHO) estimates that the true number of cases of food-borne disease is 
300-350 times higher than those of the recorded cases $[6,7]$. Food materials are considered as a major source of contamination with chemical and biological factors. It is estimated that $70 \%$ of the infectious diseases are transmitted to human via contaminated food, and more than 450 types of viral, parasitic, fungal, and microbial diseases are transmitted to human through foods of animal origin [8]. Maintenance of food health is a prerequisite for maintenance of community health,which is a major development index [9]. This could only be achieved via education and improvement of awareness level in people of different social groups and classes [10]. Education is an important development index, having close relationship with the economic status and social and cultural quality of life [11]) Effective education could lead to changes in the learners' behavior in the three aspects of knowledge, attitude, and practice. In this respect, achievement of a desirable result requires evaluation of the current status, employment of different educational approaches, and comparison of effectiveness of the approaches [12]. Then, by applying more effective educational interventions, awareness level and consequently performance of target groups would be improved [13]. The individuals in charge of facilities producing pastry, poolak, and rock candy comprise a group effective on the food health in the community. Training of these people about food health with the aim of enhancement of their knowledge, attitude, and practice could play an important role in achievement of food safety [14-16].

\subsection{Methods and Materials}

This is an interventional analytical study carried out in a cross-sectional manner in 10 months. The target population was 180 individuals in charge of facilities producing pastry, poolak, and rock candy in Shahr-e-kord. In the study, we used the Philip-Seaman's method [17]. We had two groups of people; each consists of 60 people in charge of the facilities. One group would attend the face-to-face training courses of vocational school, and the other group would attend the distance courses. Then, from each group, 30 people were selected using simple randomized sampling to include in the study. To this end,the list of all people in charge of the facilities were firstly prepared and a number was assigned to each;1-90 to those in the pastry production facilities and 1-120 to those in the poolak and rock candy producing facilities. From each group, 30 individuals were randomly selected. The participants were referred by the environmental health inspectors to the vocational schools to obtain general heath training certificate. The training course was held in two weeks, in 40 hours. Simple randomized sampling was used to determine the food chemical contamination. The questionnaire contained 15 items addressing knowledge, with answers in the value range of $0-15$. The standard deviation for knowledge scores was considered 3- 15.5. With the confidence of $95 \%$, test power of $85 \%$, and statistically significant mean difference for the two groups if the value is 1.5 or above, the sample size was calculated from the following formula:

$$
\begin{aligned}
& N=\frac{\left(\mathrm{Z} 1-\alpha^{1 / 2}+\mathrm{Z} 1-\mathrm{B}\right) 2}{\mathrm{~d} 2} \\
& N=\frac{(1 / 96+0 / 84) 2}{(0.36) 2}=60
\end{aligned}
$$

$\mathrm{N}=2+60=62$

The data was analyzed using SPSS software version 16 , by the chi square and paired t-test.

\subsection{Results}

According to the data provided in this servey the highest and lowest number of participants belonged to the 31-40 and 51-60-years age groups, respectively. 
With regard to the working history, the highest frequency was observed for working experience less than five years, and then 6-10 years, while the lowest number of participants having the working history of 16-20 years. With regard to the education level, most people in charge of the facilities had high school education level. This also comes true for the control group. According to the results of T-test, the mean knowledge levels before and after the educational intervention were significantly different for the face-to-face and distance training groups $(p<0.05)$. The difference was not statistically significant for the control group ( $p>0.05)$. The mean score change was the highest for the people from pastry production and those from the poolak and rock candy production facilities for the face-to-face and distance training groups, respectively. The difference was not statistically significant for the control group .According to the results obtained from T-test, in the faceto-face training group, the knowledge score after training changed significantly for all age groups, except for the sale persons in the age group below $21(\mathrm{p}<0.05)$. The difference was statistically significant for all age groups in the distance training group $(\mathrm{p}<0.05)$. In the control group, the difference was statistically significant only for the age group 41-50 $(p<0.017)$. The mean score changes in the face-to-face and distance training groups were the highest in the age range of 41-50 and $31-40$, respectively. The difference was not statistically significant in the control group. The results of t-test indicated that, for all the education levels, the mean knowledge scores significantly changed after the educational intervention $(p<0.05)$. In the control group, the change was statistically significant only for primary school and secondary school education levels. The mean changes in the scores were the highest in the secondary school and academic education levels for the face-to-face and distance training groups, respectively. In the control group, the difference between different education levels was not significant. Tables 1,2 have showed Comparison average score awareness before and after the intervention groups studied.

Table 1: Comparison average score awareness before and after the intervention groups studied in Shahr-e-kord -2011

\begin{tabular}{|c|c|c|c|c|c|}
\hline \multirow{2}{*}{ Variables } & $\begin{array}{c}\text { Group } \\
\text { education(schools) }\end{array}$ & $\begin{array}{c}\text { Distance education } \\
\text { groups(manual) }\end{array}$ & \multicolumn{2}{|c|}{ Controls } & \multicolumn{2}{|c|}{ X2 } \\
\cline { 2 - 6 } & $\mathrm{M}=(\mathrm{SD})$ & $\mathrm{M}=(\mathrm{SD})$ & $\mathrm{M} \pm(\mathrm{SD})$ & $\mathrm{F}$ & $\mathrm{p}$ \\
\hline $\begin{array}{c}\text { Score of } \\
\text { awareness } \\
\text { before } \\
\text { intervention }\end{array}$ & $45.4 \pm(8.88)$ & $43.46 \pm(10.34)$ & $47.14 \pm(9.47)$ & 2.168 & 0.117 \\
\hline $\begin{array}{c}\text { Score of } \\
\text { awareness after } \\
\text { intervention }\end{array}$ & $81.2 \pm(10.15)$ & $60 \pm(8.91)$ & $48.12 \pm(8.60)$ & 20.115 & 0.000 \\
\hline
\end{tabular}

\section{Discussion}

With regard to the age, the findings showed that most participants were in the age range of 31-40.Thus, the study population was fairly young. In a study by $\mathrm{Ka}$ bir et al., the knowledge, attitude, and practice of female hair dressers in Ardebil was evaluated. Furthermore, the relationship between these items on the one hand, and the methods of AIDS and hepatitis control and prevention on the other hand was evaluated. It was observed that younger hairdressers had better performance in this respect [18].

However, in the current study, we could not find a statistically significant relationship between the age on the one hand, and health knowledge and practice on the other hand. After delivering the trainings in the face-to-face training group, the highest and lowest knowledge score improvements were observed for the age groups of 41-50 and under 21, respectively. In the distance training group, the highest and lowest knowledge score improvements were observed in the age groups of 31-40 and above 60 ,respectively. The people in charge of the facilities had a fairly acceptable edu- 
cation level. However, in spite of this and also the importance of avoiding the use of artificial colors in food products, higher education level does not translate into higher knowledge level about the adverse effects of food colors.

In both the face-to-face and distance training groups, the highest knowledge score improvements were observed for participants with the primary school education level.

\section{Acknowledgements}

The authors wish to thank the Food and Drug Administration for its cooperation in fulfillment of the tests. Furthermore, kind cooperation of the research and health chancellors of Tehran University of Medical Sciences and Shahr-e-kord University of Medical Sciences is highly appreciated.

\section{References}

[1]Farzianpour, F., Rahimi Fouroshani, A., Hosseini, SH., Hosseini, S.,Hosseini, S.SH. (2012), A comparison between two educational methods of on diabetic patients in Iran. 2nd International Conference on Economic, Education and Management (ICEEM 2012):13-18

DOI:978-988-19750-3-4/10/\$25.00

(C) 2012 Hong Kong Education Society, Hong

[2]Pourahmadi, J., (2006), [General Toxicology].1st ed. Publish Samat.

Tehran-Iran: 178-184(Persian).

Sahari, MA.,(2002), [Chemistry of colorants in food] Persian. $1^{\text {st }}$ ed. Tehran: Andishmand: 9-14.

[3]Hinton DM, US FDA.,(2000), Redbook II= immunotoxicity testing guidelinesand research in immunotoxicity evaluations of food chemicals and new food proteins. Toxicol pathol: 28(3): 46778.

[4]Miller ,GD,. Drewnowski ,A,. Fulgoni ,V,. Heaney RP, .King ,J,. Kennedy

,E,. (2009) ,It is time for a positive approach to dietary guidance using nutrient density as a basic principle. J Nutr: 139: $1-5$.

[5]Arden GB,barker FM.,(1991), Canthaxanthin and the eye.A critica toxicological assessment.j Toxicol-Cut \& Ocular Toxicol; 10: 115-135.

[6]Scientific Opinion on the re-evaluation Tartrazine (E 102).(2009), European Food Safety Authority (EFSA), Parma, Italy Journal: 7(11):1331.

[7]Corsetti , A., and Settanni, L.,(2007), Lactobacilli in sourdough fermentation, Food Research International; 40: 539-558 [8]Farzianpour ,F., Sadaghipour ,H,,Hovida ,H,,Maaraf ,H,,Reazaei , H,,Rezvani ,SM., (2007), The Health of Adults in the Developing World Boushra publisher,Tehran. 2nd; 296-297[Persian]. [9]Farzianpour , F., (1999),Health education effectiveness and efficiency Solaleh nikan publisher, Tehran.2nd; 10-50 [Persian].

[10]Farzianpour, $\quad F$, Azary, S,,Ahmady ,B, ,Batabi ,A,,Pouransary ,Z, Shojaeizadeh

, D and et al. , (2003-a),Public Health\& Human Ecology. Arjomand publisher, Tehran; 239-269[Persian].

[11]Farzianpour, F., Tajvar, M.,(2003-b), Elderly Health and A review of various aspects of their life .Nasle farda publisher, Iran-Tehran; 13-130[Persian].

[12]Farzianpour, F., Batabi, F., Jahead Gh.R, Youneasian M, Mahvi A.H.,

(2011),Comparing the effect of two methods of verbal and distanse(presenting educational booklet) education on promoting the awareness and practice of workers in foodstuffs distribution and preparation centers in semnan., The First International \& 4th National Congress on Health Education Promotion. 16-19

May 2011, Tabriz-Iran; 1, Supplement: 213-214

[13] Lin, CS., Shoaf, SE., Griffiths, Jc.,1992),(pharmacokinetic data in the 
Evaluation of the safety of food and color additives,.,.Regul Toxicol.5

pharmacol;15(1):62-72.

[14]Collins, TF., Sp rando, R1., Shackelford, ME., Hansen ,DK., Welsh, jj .,(1999),

Food and Drug Administration proposed testing guidelines for reproduction studies. ", Revision Committee. FDA Guidelines for Developmental Toxicity andReproduction, Food and Drug Administration. Regul Toxicol; 30(1):29-38.

[15]Pratima ,Rao., (2008), Risk assessment of synthetic food colures case study
inHyderabad, India. Int. J. Food Safety, Nutrition and Public Health; 1( 1):13-18 [16]Ghannadi , A., (2008), [Antocyanins of barberry: A valuable source for providing natural colors] Persian. Pajuhesh and Sazandegi; 9(3): 36-41.

[17]kabir, A., Seyed vahid bae ,SV.,Siamak khaleghi ,S .,(2010), Knowledge,Attitude \&practice of Iranian specialist regarding Hepatitis B\&C. hep mon., 10(3): 176-182

http://racr.shmtu.edu.cn/en_index.asp. 